\title{
Use of remote imagery to verify modelled streambank retreat rates
}

\author{
$\underline{\text { P. Binns }}$ \\ Department of Natural Resources and Mines, Toowoomba, Queensland \\ Email: Peter.Binns@dnrm.gld.gov.au
}

\begin{abstract}
The Source Catchments model attributes fractions of the sediment load carried by the rivers discharging into the Great Barrier Reef (GBR) lagoon, to specific sources - namely, hillslope, gully and streambank erosion. This study was conceived to determine whether it was possible to derive estimates of streambank retreat rates in a river discharging into the GBR lagoon, by using remote imagery. This remote imagery was to be in the form of readily available historical aerial photographs and more recent satellite imagery. Any usable estimates of streambank retreat rates that were obtained, were to be evaluated in regard to their suitability for the verification of the algorithms in the streambank erosion module in the Source Catchments model.
\end{abstract}

The streambank mapping exercise was undertaken using sets of historical aerial photographs and more recent satellite imagery covering some 150-kilometres in the middle reaches of the Mary River. This river carries a disproportionately large sediment load relative to its volumetric discharge. The Source Catchments model attributes this differentiating characteristic to above-average rates of streambank erosion in the Mary River.

The likely inundation extents associated with bankfull discharge were delineated in the various sets of historical imagery. This process yielded a time series of bankfull discharge polygons covering the subject reaches. Estimates of bankfull width were then obtained by laying transects at 500-metre intervals along and at right angles to the river centerline, in each set of images. This provided measurements of bankfull width at each transect location in each polygon in the time series. Digital elevation data obtained from airborne LiDAR surveys was used to aid verification of the bankfull width estimates derived from contemporaneous remote imagery. Streambank retreat rates were then determined on the basis of the change in bankfull width in the intervals between the sets of images in the time series. The statistical significance of the long-term rate of streambank retreat at each transect location was assessed by fitting the non-parametric Theil-Kendall Robust Line to the data.

Changes in bankfull width varied substantially along the studied reaches, but did show a somewhat remarkable lack of temporal variability at the various transect locations. Spatial variability appeared more closely related to stream sinuosity than it did to presence of upper storey riparian vegetation. Notwithstanding the observed uniformity of the long-term trends, temporarily accelerated streambank retreat rates were associated with major floods.

This study confirmed that the streambank retreat rates in the Mary River are relatively high when compared to other rivers discharging into the GBR lagoon. Furthermore, the broadscale retreat rate values presently adopted in Source Catchments model were found to be reasonably accurate. However, at a finer scale the modelled and measured estimates of retreat rates were somewhat disparate. The nature of this study precluded definitive identification of causative factors, but indicated that some refinement of the streambank erosion algorithms, or the applied data values, might be required if this disparity was to be addressed.

Keywords: $\quad$ Source Catchments model, Mary River, remote imagery, model verification, streambank retreat 


\section{INTRODUCTION}

\subsection{Background}

There have long been concerns regarding anthropogenic impacts on the quality of water entering the Great Barrier Reef (GBR) lagoon (e.g. Baldwin et al., 1987; and Furnas \& Brodie, 1996). Such concerns led in 2003 to the establishment of water quality targets for the 35 catchments discharging into the GBR lagoon (Waters et al., 2014). The regional water quality targets relate to suspended sediment; dissolved and particulate-entrained nitrogen and phosphorus; and certain PSII herbicides.

The GBR Source Catchments model is used to inform and prioritize investment decisions intended to facilitate improved water quality in streams in GBR catchments. It is a multi-module model that generates regional scale, average annual sediment, nutrient, and herbicide residue budgets for the modelled river networks (Waters et al., 2014). The model breaks a major river catchment into a series of component links, broadly akin to subcatchments (refer Figure 1, below).

The Source Catchments model uses algorithms in the Dynamic SedNet Plugin to partition the source of sediment loads between terrestrial (i.e. hillslope and gully) and streambank erosion, on a link-by-link basis. The streambank erosion rate algorithm in the Dynamic SedNet Plugin has the following form (Ellis \& Searle, 2014):

Where: $M A B E$

$R R$

$H$

$L_{l}$

$B D_{d r y}$

$B E$

$$
M A B E=R R \times H \times L_{l} \times B D_{d r y} \times B E
$$

Equation 1

$$
\begin{aligned}
& =\text { mean annual bank erosion rate }(\mathrm{t} / \mathrm{yr}) \\
& =\text { streambank retreat rate }(\mathrm{m} / \mathrm{yr}) \\
& =\text { erosion-contributing (not physical) bank height }(\mathrm{m}) \\
& =\text { river length }(\mathrm{km}) \text { represented by a model link }(I) \\
& =\text { dry bulk density of eroded sediment }\left(\mathrm{t} / \mathrm{m}^{3}\right) \\
& =\text { bank erodibility. }
\end{aligned}
$$

Bank erodibility, $B E$, is defined as follows (Ellis \& Searle, 2014):

$$
\begin{aligned}
& B E=(1-\operatorname{MIN}(\text { RipVeg, MaxVegEffectiveness })) \times \text { SoilErod } \\
& \text { Equation } 2 \\
& \text { Where: RipVeg } \\
& =\text { the proportion of intact riparian vegetation (as decimal fraction) } \\
& \text { MaxVegEffectivness } \\
& \text { SoilErod } \\
& =\mathrm{a} \text { term constraining the upper limit the effectiveness of the vegetation } \\
& =\text { erodibility of streambank material }(0-1 \text {, rock to soil })
\end{aligned}
$$

The Dynamic SedNet Plugin assumes that the streambank retreat rate (i.e. $R R$ in Equation 1) is a function of stream power at bankfull discharge, and has the following form (Ellis \& Searle, 2014):

$$
R R=k \times \rho_{w} \times g \times S_{x} \times Q_{b f} \times M_{f}
$$

\section{Equation 3}

Where: $\quad k \quad=$ a bank erosion coefficient (default value of 0.00004 )

$\rho_{W} \quad=$ density of water (assumed $1000 \mathrm{~kg} / \mathrm{m}^{3}$ )

$g \quad=$ gravitational acceleration (assumed $9.81 \mathrm{~m} / \mathrm{s}^{2}$ )

$S_{X} \quad=$ streambed slope $(\mathrm{m} / \mathrm{m})$

$Q_{b f} \quad=$ bankfull discharge $\left(\mathrm{m}^{3} / \mathrm{s}\right)$

$M_{f} \quad=$ a modeller-assigned bank erosion management factor $(0.71-1.00)$

To date, validation of the parameters in equations 1, 2 and 3 has relied on establishing concurrence between model predictions and monitoring data (Waters et al., 2014). Notwithstanding the level of agreement hitherto observed, parametric and algorithmic uncertainty still applies to the estimates of streambank erosion based on these equations. To address this uncertainty, the SedNet User Guide (Wilkinson et al., 2008) recommends the use of historical aerial photographs, captured over several decades, to verify stream bank erosion rates at multiple locations in a catchment - a recommendation adopted for this study.

The Mary River catchment is the southernmost river discharging into the GBR lagoon. Monitoring data has revealed that when compared to other streams discharging into the lagoon, this river carries a disproportionately large sediment load relative to its volumetric discharge (Furnas, 2003; Brodie et al., 2011; Fentie et al., 2014 and Bartley et al., 2015). This increased sediment load is replicated in the Source Catchments model by allowing disproportionately high rates of streambank erosion (DeRose et al., 2002; and Bartley et al., 2015). However, confidence in this apportionment is not high. Accordingly, the Mary River would appear to be a good candidate for evaluating the use of remote imagery for quantifying streambank erosion rates, and verification of the streambank erosion algorithms in the Dynamic SedNet Plugin. 


\subsection{Measuring planform change using remote imagery}

There is a significant history pertaining to the use of remotely captured imagery to measure changes in stream morphology and geometry (e.g. Brice, 1971; Childers \& Jones, 1975; Williams, 1978 and Hooke, 1984). Since these initial studies, a diverse variety of methods have been developed to measure planform changes in streams in remotely captured imagery. The more common measurement methods applied include meander, centreline or thalweg migration; the areal extents of erosion and deposition; bankfull width; and bank recession. After a preliminary evaluation of the various methods, bankfull width was found to be the most suitable where remote imagery is being used to quantify change.

\subsection{Aims and objectives}

The aim of this study was to determine whether:

(a) Usable estimates of bankfull width were able to be derived from historical aerial photographs and more recent satellite imagery; and

(b) The temporal variation in bankfull width estimates derived from this imagery could then provide:

i. Evidence of the severity and spatial and temporal extent of any streambank retreat;

ii. Reasonable estimates of the associated retreat rates; and

iii. Validation of the retreat rates derived and used in the Source Catchments model.

\section{METHODOLOGY}

\subsection{The study area}

The Mary River catchment covers a total area of some $9600 \mathrm{~km}^{2}$. The river runs in a northerly direction, parallel to the Queensland coast, for much of its course (refer Figure 1, below). The climate is sub-humid and subtropical. Average annual rainfall varies from $\sim 2000 \mathrm{~mm} / \mathrm{yr}$ in the far southeast, to $\sim 800 \mathrm{~mm} / \mathrm{yr}$ in the west.

The study covered five contiguous reaches of the river between its upstream confluence with Yabba Creek, and the bridge crossing the river at Tiaro - a total middle thread distance of some 150 kilometres or about $50 \%$ of the river's total length. This 150 kilometre section of the river represents 17 links in the Source Catchments model (refer Figure 1, below) and had previously been identified as being seriously affected by streambank erosion (e.g. DeRose et al., 2002). The dissection of this section of the river into five reaches was necessitated by there being no single sets in the series of aerial photographs or satellite image tiles that simultaneously covered the subject section of the river in its entirety.

The Miva gauging station is near the middle of the five reaches assessed in this study, and is the gauging station with the longest duration of daily discharge data (i.e. 2/01/1910 to the present). Notably, the ten largest peak daily discharges at this gauge have all occurred in or subsequent to 1955.

\subsection{Remote imagery}

The aerial photographs used in the study included a mixture of colour and black and white images, which were captured at a wide variety of times and intervals subsequent to 1940, at scales varying from 1:15 000 to 1:50 000. The images were scanned at a 300 dpi resolution and imported into ESRI ${ }^{\circledR}$ ArcMap ${ }^{\mathrm{TM}}$, prior to georeferencing.

Five ground control points (GCPs) were initially selected in each image for the geo-referencing process. The 2015 satellite imagery in Google Earth ${ }^{\circledR}$ was used as the base layer for identifying the GCPs in the aerial photographs. The number and distribution of GCPs was then augmented to incrementally and optimally improve the geo-referencing root mean square of error (RMSE). The resultant median RMSE value for all of the geo-referenced aerial photographs was 7.4 metres. Due to the autocorrelation of the spatial error applicable to proximate points in the one image, the geo-referencing RMSE values were not necessarily an appropriate gauge of the margin of error applicable to the individual bankfull width measurements.

The historical satellite imagery available in the standard version of Google Earth ${ }^{\circledR}$ was also used in this study. Generally four or more sets of high resolution historical images, covering the five subject reaches, were available for the period subsequent to 2009.

A 1-metre grid bare-earth digital elevation model (DEM) was also available for the Mary River catchment. This data had been derived from airborne LiDAR surveys undertaken in either 2008 or 2009, and covered areas north and south of latitude $26.7^{\circ} \mathrm{S}$, respectively. 


\subsection{Bankfull width measurement}

In this study, bankfull discharge was considered to occur at the point of incipient flooding. In gauged reaches, incipient flooding was judged to correspond to the most substantial inflection point detected in the uppermost part of the gauge's stage-discharge curve (see McCandless \& Everett, 2002). Bankfull discharges at the three gauging stations in the study reaches were found to occur at average recurrence intervals of 2.32, 3.54 to 4.24 years. In all cases, the river depth at bankfull discharge was somewhat less than the actual bank height.

Polygons representing the stream width at bankfull discharge were hand digitised from the aerial photographs and satellite imagery, at a viewing scale of approximately 1:2 500. The extents of the polygons were judged visually, based on observable changes in bank slope; evidence of scouring, bank undercutting or slumping; changes in vegetation; and/or the presence of exposed or deposited materials on point bars or the like.

The bankfull tool in the River Bathymetry Toolkit (McKean, et al., 2009) was applied to progressively 'flood' the detrended LiDAR-derived DEM, and establish the point of incipient flooding, so generating a bankfull polygon for the subject reaches in either 2008 or 2009 . The resultant polygon was then used to test the accuracy and reliability of bankfull polygons derived from the aerial photography and satellite imagery. This process indicated that in the Mary River, floodplain inundation tended to occur primarily through breaches in the natural levees, where tributary streams or gullies entered the river channel, rather than by the direct overtopping of the levees. This was consistent with the estimates of bankfull discharge that had been previously obtained from the stage-discharge curves for the three gauging stations located on the study reaches.

To obtain representative estimates of bankfull width in each set of images, 301 transects were laid out, 500 metres apart, at right angles to the 150-kilometre long, stream centerline, in ArcMap ${ }^{\mathrm{TM}}$. The digitised bankfull polygons, each derived from a single set of images, were used to repeatedly clip to length the original transect polylines. This produced a time series of bankfull widths for each transect location. The streambank retreat rate in the period between successive sets of images was then estimated as follows:

$$
R_{j}=\frac{w_{j t_{2}}-w_{j t_{1}}}{t_{2}-t_{1}}
$$

Equation 4

Where: $\quad R_{j} \quad=$ retreat rate $(\mathrm{m} / \mathrm{yr})$ along the $j^{\text {th }}$ transect between times $t_{2}$ and $t_{1}$

$W_{j t 2}=$ bankfull width (m) at the location of the $j^{\text {th }}$ transect at time $t_{2}$

$W_{j t 1}=$ bankfull width (m) at the location of the $j^{\text {th }}$ transect at time $t_{1}$

$t_{2}=$ date $(\mathrm{yr})$ when image \#2 was captured

$t_{1} \quad=$ date $(\mathrm{yr})$ when image \#1 was captured

The Theil-Kendall Robust Line - a non-parametric analogue of the least squares linear regression equation was used to evaluate the temporal changes in bankfull width (i.e. the streambank retreat rates). Kendall's tau statistic provides the test of statistical significance for the Theil-Kendall Robust Line (Helsel \& Hirsch, 2002).

\subsection{Other variables}

Bank height estimates at each transect location were obtained by applying the same 500-metre interval transects used to estimate bankfull width, to the LiDAR-derived DEM. The height of the lowest of the two banks along each transect (i.e. the bank first overtopped) was recorded as the bank height at that location.

A sinuosity value, which represented valley length divided by river length, was calculated for each of the 301 nodes formed where transects intersected the stream centerline. At each node, valley length was determined as the lateral distance separating the adjacent upstream and downstream nodes from one another. Owing to the placement of transects, the river length separating these two nodes was 1000 metres. The resultant sinuosity value was expressed as a decimal fraction, with a maximum value of one for a perfectly straight reach.

The cover associated with upper storey woody riparian vegetation was also estimated by determining the cumulative length of each cross-river transect intersected by tree crowns in the 2009 satellite imagery. The crown cover was then expressed as a decimal fraction of the planar transect length.

\section{RESULTS}

\subsection{Streambank retreat}

Changes in bankfull width varied markedly along the studied reaches. Where changes were observed, the rates of change were a remarkably consistent trait for the duration of the available imagery (i.e. up to 70 years). Overall, the mean and median changes in bankfull width equated to rates of 0.35 and $0.19 \mathrm{~m} / \mathrm{yr}$ respectively. 
While streambank erosion was dominant, at around $30 \%$ of the transect locations either bankfull width remained relatively stable over time; or there was long-term accretion and narrowing of the channel. Figure 1 shows the transect locations where there were statistically significant $(p=0.05)$ increases or decreases in bankfull width, as determined using the Theil-Kendall Robust Line.

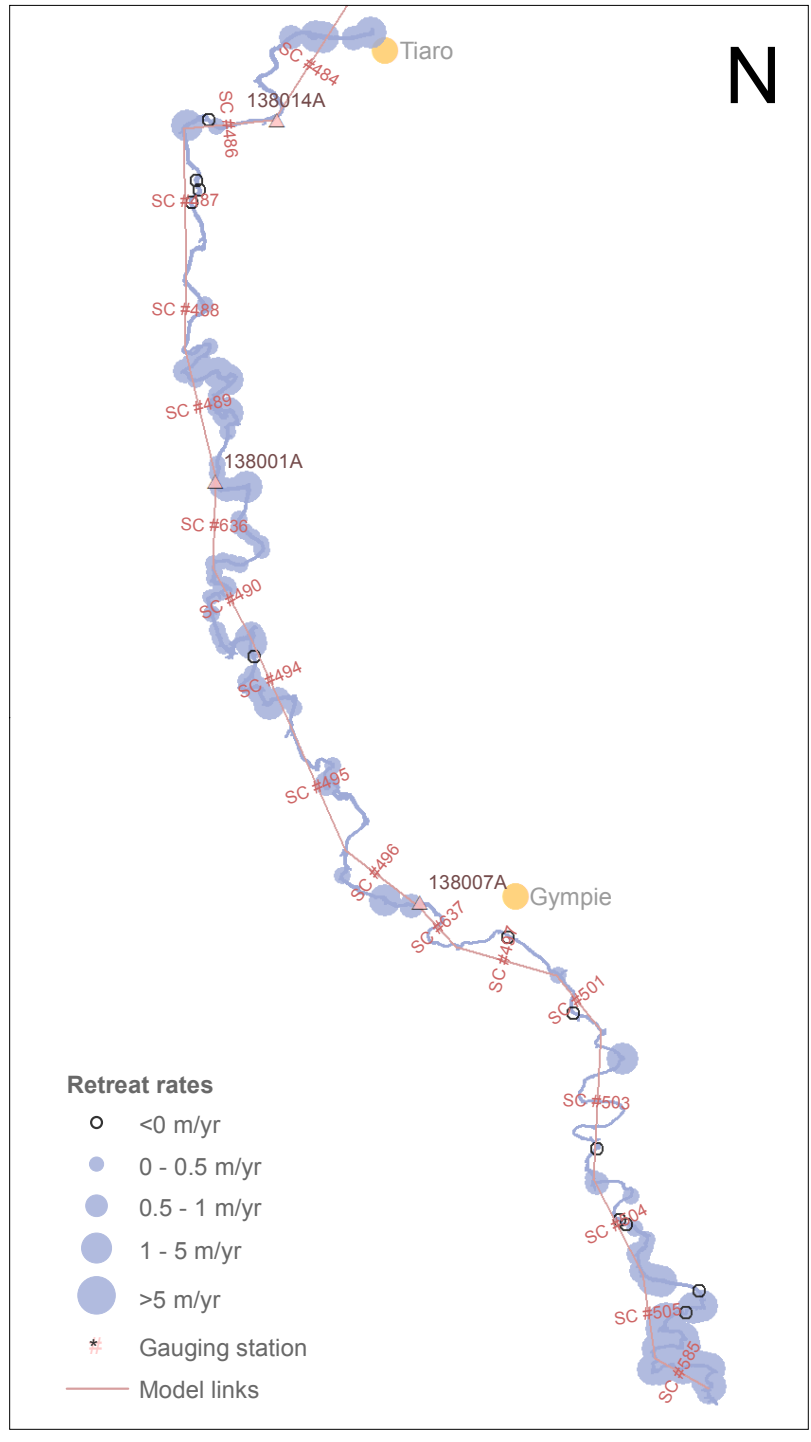

Figure 1. Statistically significant $(p=0.05)$ streambank retreat rates
Figure 2 presents a bi-plot of the results of a principal component analysis (PCA) that compared retreat rates, sinuosity, riparian tree cover and bank height at each of the 301 transect locations. Collectively, the first two principal components (i.e. PC1 and PC2) account for $66 \%$ of the variability in the data. The biplot suggests that when compared to riparian tree cover, sinuosity has a stronger relationship with streambank retreat rates. Bank height appeared entirely unrelated to retreat rate. However as with all forms of correlation, any relationship evident in a PCA biplot does not in itself prove causality.

Casual observations made during the analysis of the imagery had identified two forms of interaction between riparian vegetation and bank erosion. At certain locations there was a recurrent pattern involving erosive scouring and loss of vegetation during major floods, followed by rapid recruitment and reestablishment of trees on the freshly exposed sediment and streambanks. A subsequent flood initiated a recurrence of this process. In general though, streambank slumping and wet earth flows appeared to be the dominant forms of bank retreat. Importantly, these particular mass movement processes seemed to occur irrespective of the presence or absence of riparian vegetation within the channel banks.

\subsection{Validation of Source Catchments modelling}

Figure 3 provides a comparison of the retreat rates currently applied to the 17 links in the Source Catchments model for the Mary River (refer Figure 1), and the average retreat rates obtained in this study for those same links. While there is no evidence of a relationship between the modelled and measured values in Figure 3, the average value for all of the model links of $0.32 \mathrm{~m} / \mathrm{yr}$, is remarkably similar to the mean retreat rate in this study of $0.35 \mathrm{~m} / \mathrm{yr}$. This suggests that at a broad scale, the process currently used to establish concurrence between model predictions and monitoring data has been successful. On the other hand, the obvious disparity between the rates for the individual links in Figure 3 indicates there is scope to improve the parameterisation of the relevant Dynamic SedNet Plugin algorithms, as used in the Source Catchments model.

A comparison of the values currently applied to the riparian vegetation variable, RipVeg, in the bank erodibility algorithm (Equation 2), and the vegetative cover values for those same links obtained in this study, found that a statistically significant relationship existed between the two sets of values $\left(y=0.56 x-17.87, \mathrm{r}^{2}=0.70, \mathrm{~F}=\right.$ $35.03, \mathrm{p}<0.001)$. However, the vegetative cover values derived in this study were generally some $45 \%$ less than those currently applied to the same links in the Source Catchments model.

Comparing the bank height, $H$, applied to links in the Source Catchments model (Equation 1), and the average bank height for those same links in this study, also yielded a strong relationship $\left(y=1.03 x-7.68, \mathrm{r}^{2}=0.68, \mathrm{~F}\right.$ 


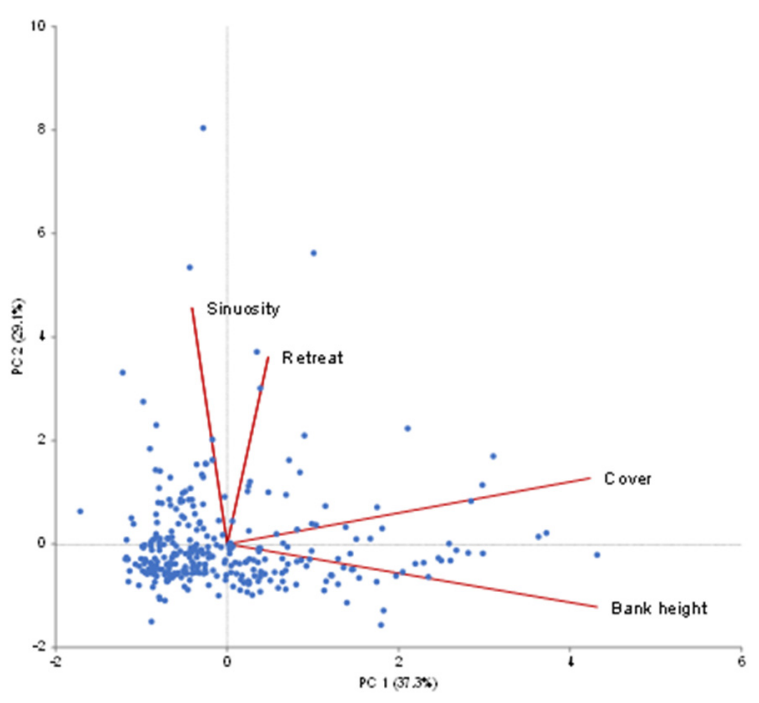

Figure 2. Bi-plot of the results of a PCA comparing retreat rate, sinuosity, riparian tree cover and bank height

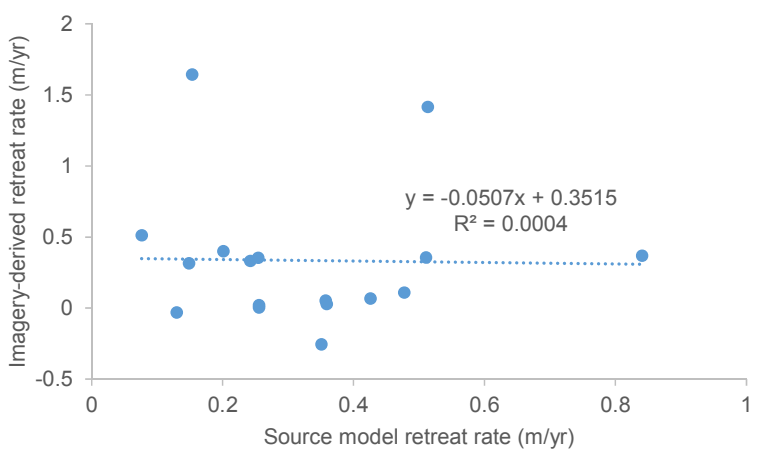

Figure 3. Comparison of streambank retreat rates in the Source Catchments model and those derived from this study

observed along the studied reaches. However, the adopted assess the identification of causative factors that might provide a statistically robust explanation for this spatial variability. Nonetheless, sinuosity appeared to be a better indicator of a streambank's susceptibility to erosion, when compared to the presence (or absence) of upper storey riparian vegetation, which was almost always confined to within the channel banks in the subject reaches of the river.

\section{CONCLUSIONS}

This study demonstrated that usable estimates of bankfull width and streambank retreat rates were able to be derived from the historical aerial photographs and more recent satellite imagery covering the middle reaches of the Mary River. However, the observed streambank retreat rates were relatively high and had remained relatively constant for up to 70 years. Hence, some caution is needed if the applied methodology is to be used to validate similar modelling of other rivers, where streambank erosion might be of a lower magnitude or more episodic in nature.

Casual observations would also suggest that riparian vegetative cover along the middle reaches of the Mary River is generally less extensive than that typically found along other streams modelled using the GBR Source Catchments model. Consequently, any propensity for more extensive upper storey vegetation to directly obscure or shade the channel banks in the aerial photographs or satellite imagery covering other streams, could pose an additional constraint on the extension of this methodology to those catchments.

Notwithstanding the above, it is evident that the retreat rates presently applied to the Mary River, as a whole, in the Source Catchments model, are not totally unreasonable. On the other hand, the information gained here 
P. Binns, Use of remote imagery to verify modelled streambank retreat rates

would suggest at a finer scale (i.e. individual model links) there is scope to improve the parameterisation of the algorithms used to estimate bank retreat and erosion in the Source Catchments model (i.e. equations 1, 2 and 3 , above), and so enhance the confidence attributable to the modelled outcomes.

\section{REFERENCES}

Baldwin, C., McGinnity, P. \& Byron, G. (1988). Waste discharge in the Great Barrier Reef Marine Park, in 'Workshop on Nutrients in the Great Barrier Reef Region', Baldwin, C., (ed.), Great Barrier Reef Marine Park Authority, Townsville. Qld.

Bartley, R., Henderson, A., Wilkinson, S., Whitten, S. \& Rutherford, I. (2015). 'Stream bank management in the Great Barrier Reef catchments: A handbook', CSIRO Land and Water, Canberra, ACT.

Brice, J. (1971). 'Measurement of lateral erosion at proposed river crossing sites of the Alaska pipeline', US Department of the Interior, Alaska, AK.

Brodie, J., McKergow, L.A., Prosser, I.P., Furnas, M., Hughes, A.O. \& Hunter, H. (2011). Sources of Sediment and Nutrient Exports to the Great Barrier Reef World Heritage Area, CSIRO Land \& Water, Canberra, ACT.

McCandless, T.L. \& Everett, R.A. (2002). 'Maryland Stream Survey: Bankfull discharge and channel characteristics of streams in the Piedmont Hydrologic Region', US Fish \& Wildlife, Annapolis, MD

Childers, J.M. \& Jones, S.H. (1975). Channel erosion surveys along TAPS Route, Alaska, 1974, US Department of the Interior Geological Survey, Anchorage, Alaska, AK

DeRose, R.C., Prosser, I.P., Wilkinson, L.J., Hughes, A.O. \& Young, W.J. (2002). 'Regional Patterns of Erosion and Sediment and Nutrient Transport in the Mary River Catchment, Queensland', Technical Report 37/02, CSIRO Land and Water, Canberra, ACT.

Ellis, R.J. \& Searle, R.D. (2014). 'Dynamic SedNet Component Model Reference Guide: Concepts and algorithms used in Source Catchments customisation plugin for Great Barrier Reef catchment modelling'. Queensland Department of Science, Information Technology, Innovation and the Arts, Bundaberg, Qld.

Fentie, B., Ellis, R., Waters, D. \& Carroll, C. (2014). 'Modelling reductions of pollutant loads due to improved management practices in the Great Barrier Reef catchments', Burnett Mary NRM region Technical Report Volume 7, Queensland Department of Natural Resources and Mines, Brisbane, Qld.

Furnas, M. (2003). Terrestrial Runoff to the Great Barrier Reef, Australian Institute of Marine Science, Townsville, Qld

Furnas, M.J. \& Brodie, J. (1996). Current status of nutrient levels and other water quality parameters in the Great Barrier Reef, in 'Downstream Effects of Land Use', Hunter, H.M., Eyles, A.G. \& Rayment, G.E., (eds.), Queensland Department of Natural Resources, Indooroopilly, Qld.

Helsel, D.R. \& Hirsch, R.M. (2002). Statistical Methods in Water Resources, in 'Techniques of Water Resource Investigations of the United States Geological Survey’, US Geological Service, Denver, CO.

Hooke, J.M. (1984). Changes in river meanders a review of techniques and results of analyses, Progress in Physical Geography, 8:473-508.

McKean, J., Nagel, D., Tonina, D., Bailey, P., Wright, C.W., Bohn, C. \& Nayegandhi, A. (2009). River Bathymetry Toolkit: A GIS toolkit for mapping the in-stream environment, U.S. Forest Service, Boise, ID.

Simon, A. \& Downes, P.W. (1995). An interdisciplinary approach to evaluation of potential channel instability in alluvial channels, Geomorphology, 12:215-232.

Waters, D.K., Carroll, C., Ellis, R., Hateley, L., McCloskey, G.L., Packett, R., Dougall, C. \& Fentie, B. (2014). 'Modelling reductions of pollutant loads due to improved management practices in the Great Barrier Reef catchments - Whole of GBR', Technical Report, Volume 1, Queensland Department of Natural Resources and Mines, Toowoomba, Qld.

Wilkinson, S., Henderson, A., Chen, Y. \& Sherman, B. (2008). 'SedNet User Guide: SedNet - Sediment and Nutrient Budgets for River Networks', CSIRO Land and Water, Canberra, ACT.

Williams, G.P. (1978). Bank-full discharge in rivers, Water Resources Research, 14:1141-1154. 